\title{
Prevalence and correlates of anemia among elderly population of rural Nalgonda: a cross-sectional analytic study
}

\author{
M Malhotra V. ${ }^{1}{ }^{*}$, R Kabra P. ${ }^{2}$, Bhayya S. ${ }^{3}$, Malhotra R. ${ }^{4}$ \\ DOI: https://doi.org/10.17511/ijphr.2016.i4.06 \\ 1* Varun M Malhotra, Associate Professor, Department of Community Medicine, Kamineni Institute of Medical Sciences, Nalgonda, \\ Telangana, India. \\ 2 Pratyush R Kabra, Assistant Professor, Department of Community Medicine, Kamineni Institute of Medical Sciences, Nalgonda, Telangana, \\ India. \\ 3 Bhayya S, Professor, Department of Community Medicine, Kamineni Institute of Medical Sciences, Nalgonda, Telangana, India. \\ 4 Ritika Malhotra, Aseem Nursing Home, Panchkula, Haryana, India.
}

Background: Anemia is a global health challenge, and India is no exception. Large number of studies including NFHS-4 has quantified the prevalence of anemia among children, adolescents, women in reproductive age group, pregnant \& lactating mothers and men in age groups below 50 years. However, there is lack of community-based studies among elderly population in India. Objectives: To detect the prevalence of anemia among elderly, and identify socio-demographic and life style factors associated with the disease. Methods: This study was conducted in 11 villages in the jurisdiction of Rural Health Training Centre of a medical college in Nalgonda district of Telangana State. 331 individuals above the age of 50 years of either sex and permanent residents of the villages were included in the study. Haemoglobin levels were detected by Sahli technique. Results: The study revealed that $27.8 \%$ (95\% CI $23.2-32.8 \%)$ of study population was anemic. The prevalence of anemia was significantly higher among females than males. The study showed that prevalence of anemia was associated with advancing age, non-use of footwear, excessive alcohol consumption and history of chronic blood loss. Conclusion: The study indentifies that anemia is a significant public health problem among elderly. The authors recommend that prevalence of anemia among elderly ( $\geq 50$ years) should be included in future National Family Health Surveys to quantify its prevalence in this demographic group that is progressively increasing in size due to rising longevity.

Keywords: Anemia, Elderly, Nalgonda, Rural

Corresponding Author

Varun M Malhotra, Associate Professor, Department of Community Medicine, Kamineni Institute of Medical Sciences, Nalgonda, Telangana, India. Email: varunmalho3ra@gmail.com
How to Cite this Article

Malhotra VM, Kabra PR, Bhayya S, Malhotra R. Prevalence and correlates of anemia among elderly population of rural Nalgonda: a cross-sectional analytic study. Public Health Rev Int J Public Health Res. 2016;3(4):168-173.

Available From

https://publichealth.medresearch.in/index.php/ijphr/ To Browse article/view/48

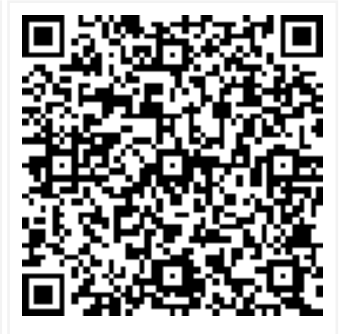

$\begin{array}{cc}\begin{array}{c}\text { Manuscript Received } \\ 2016-07-29\end{array} & \begin{array}{c}\text { Review Round } \mathbf{1} \\ 2016-08-10\end{array} \\ \text { Conflict of Interest } & \text { Funding } \\ \text { No } & \text { Nil }\end{array}$




\section{Introduction}

Anemia is defined as a condition in which the number of red blood cells, and consequently their oxygen-carrying capacity is insufficient to meet the body's physiological needs. Specific physiological needs of an individual vary with age, gender, altitude, smoking behaviour, and pregnancy. Iron deficiency is the most common cause of anemia globally, but other nutritional deficiencies (folate, Vitamin B12, and Vitamin A), acute and chronic inflammation, parasitic infections, inherited and acquired disorders of haemoglobin synthesis, RBC's production or RBC's survival, can all cause anemia [1].

Although clinical evaluation of anemia requires multiple laboratory tests to diagnose the severity, type and cause of anemia, haemoglobin concentration is a reliable indicator of anemia at the population level [2]. Anemia is an important public health problem globally. World Health Organization (WHO) estimates that 1.62 billion people globally (95\% CI 1.50-1.74 billion) which correspond to $24.8 \%$ of the world population are affected with anemia [3].

The public health significance of anemia among populations in India needs no reiteration. NFHS-4 (2015-16) for the State of Telangana reports that $51.6 \%$ of children aged 6-59 months, 55\% of women in reproductive age group (15-49 years) and $10.2 \%$ of men in most productive years of age (1549 years) are anemic [4].

In view of significant health implications of anemia especially on maternal and children's health, as well as huge social and economic loss, the government of India has initiated programmes to decrease the burden of anemia among children, adolescent girls, non-pregnant women in reproductive age group and pregnant and lactating women through direct as well as indirect interventions [5-7].

Indeed, anemia is an important public health challenge among elderly also, both in developed and developing world. Anemia in older individuals is associated with a wide range of complications, including increased risk of mortality, cardiovascular disease, cognitive dysfunction, reduced bone density and longer periods of hospitalization for elective procedures and co-morbid conditions [8]. However, there is relatively lack of interest in identifying the burden of the disease among elderly in India.
This may be due to belief that anemia is an insignificant health issue in this group as the prevalence may be low in males, and cessation of menstruation in females would compensate for inadequate bio-availability of micronutrients. This misconception reflects as conspicuous lack of studies regarding prevalence of anemia among senior citizens in India. A database published by WHO regarding studies on prevalence of anemia compiled more than 100 studies conducted in India from 1958 to 2003 [9].

The perusal of the database reveals that only three studies included individuals at the age of 50 years or above. Similarly National Family Health Survey-4 [4] has studied the anemia up to the age of 50 in females and males. The present study was undertaken to study the prevalence of anemia among elderly (aged 50 and above) residing in villages in the jurisdiction of Rural Health Training Centre (RHTC) of a medical college in rural Nalgonda (Telangana) and identify social and behavioral associates of the disease.

\section{Materials and Method}

A cross sectional analytical study was conducted in Nalgonda district of Telangana during May to August 2016. A pilot study was conducted to refine the study instrument and standardize laboratory procedures. A sample size of 300 was calculated based on WHO estimates on prevalence of anemia at $25 \%$, level of significance $5 \%$ and allowable error of $20 \%$ of the anticipated prevalence.

The sampling units (households with individuals aged 50 years or more) in all 11 villages in the jurisdiction of RHTC were identified from familyfolders maintained at the RHTC. Three hundred households with at least one individual qualifying for inclusion i.e. aged 50 years or more and of either sex were selected by random sampling. In case of presence of more than one individual in the selected household, all elderly meeting inclusion criteria were enrolled in the study.

Elderly not willing to join the study, or unavailable during the day of the visit were excluded. This sampling procedure led to inclusion of 331 individuals in the study. Haemoglobin estimation was done by Sahli technique by qualified laboratory technicians at places of residence. WHO recommended levels for diagnosis and classification of anemia [1] were used to classify the cases as mild, moderate and severe anemia. 
Data was compiled on Windows excel sheet and analyzed using statistical software Open Epi ver 3.01. Ethical clearance from the Institutional Ethics Committee and informed consent from all participants were obtained. Individuals diagnosed as anemic were provided treatment at the RHTC and referral services at the medical college.

\section{Results}

A total of 331 individuals aged 50 years and above of both sexes (160 males: 171 Females) were included in the study.
The study revealed that $92(27.79 \%)$ individuals were anemic, based on definition of anemia by WHO i.e. less than $12 \mathrm{gms} / 100 \mathrm{ml}$ in females, and less than $13 \mathrm{gms} / 100 \mathrm{ml}$ in males. Prevalence of anemia in study population as per various sociodemographic factors is presented in Table 1.

The prevalence of anemia showed a statistically significant rising trend with advancing age (Fig 1). The table also reveals that the anemia was more prevalent among females (30.26\%) than among males $(22.45 \%)$, and the difference was statistically significant. Other socio-demographic variables i.e. religion, type of family and education were found to be not associated with the prevalence of anemia.

Table 1: Distribution of Anemia based on Socio-demographic Factor

\begin{tabular}{|c|c|c|c|c|c|c|}
\hline $\begin{array}{c}\text { Characteristics/Fac } \\
\text { tor }\end{array}$ & Variable & $\begin{array}{l}\text { Number Anemic } n= \\
\qquad 92(\%)\end{array}$ & $\mid \begin{array}{c}\text { Number Non-anemic } n=239 \\
(\%)\end{array}$ & $\left|\begin{array}{c}\text { Tota } \\
1\end{array}\right|$ & \multicolumn{2}{|c|}{$\begin{array}{l}\text { P value (Chi square test) (Crude OR for } \\
\text { advancing age) }\end{array}$} \\
\hline \multirow[t]{4}{*}{ Age } & $50-59$ & $40(22.3)$ & 139 (77.7) & 179 & \multirow{4}{*}{$0.04 \#$} & 1.0 \\
\hline & 60-69 & 29 (29.9) & $68(70.1)$ & 97 & & 1.48 \\
\hline & 70-79 & $15(41.7)$ & $21(58.3)$ & 36 & & 2.48 \\
\hline & $80+$ & $8(42.1)$ & 11(57.9) & 19 & & 2.53 \\
\hline \multirow[t]{2}{*}{ Sex } & Male & 35 (21.9) & $125(78.1)$ & 160 & \multirow[t]{2}{*}{$0.02 \#$} & \\
\hline & Female & 57 (33.3) & $114(66.7)$ & 171 & & \\
\hline \multirow[t]{2}{*}{ Type of Family } & Joint & 44 (23.5) & $126(76.5)$ & 170 & \multirow[t]{2}{*}{0.65} & \\
\hline & Nuclear & $48(28.1)$ & $123(71.9)$ & 171 & & \\
\hline \multirow[t]{3}{*}{ Religion } & Hindu & $83(28.0)$ & $213(72.0)$ & 296 & \multirow[t]{3}{*}{0.77} & \\
\hline & Muslim* & $6(27.3)$ & $16(72.7)$ & 22 & & \\
\hline & Christian* & $3(23.1)$ & $10(76.9)$ & 13 & & \\
\hline \multirow[t]{6}{*}{ Education } & Illiterate & $46(27.4)$ & $122(72.6)$ & 168 & \multirow{6}{*}{0.98} & \\
\hline & Literate & $23(28.7)$ & $57(71.3)$ & 80 & & \\
\hline & Primary & $11(26.2)$ & $31(73.8)$ & 42 & & \\
\hline & Middle* & $7(30.4)$ & $16(69.6)$ & 23 & & \\
\hline & Secondary* & $3(27.3)$ & $8(72.7)$ & 11 & & \\
\hline & $\begin{array}{l}\text { Degree \& } \\
\text { above* }\end{array}$ & $2(28.6)$ & $5(71.4)$ & 7 & & \\
\hline
\end{tabular}

*Rows combined for Chi-square test, \#statistically significant

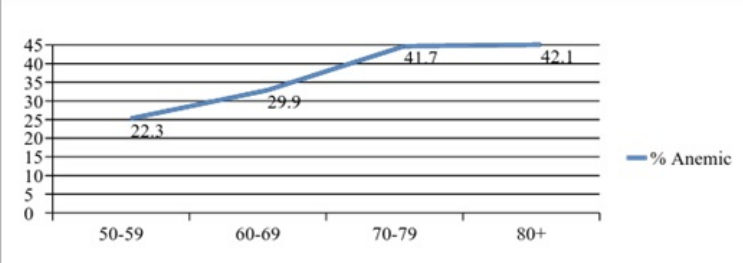

Fig-1: Rising prevalence of anemia with advancing age
Association of anemia with behavioural and life-style factors is depicted in Table 2. As evident from the table, type of diet (vegetarian/ non-vegetarian) was not associated with anemia. Smokers showed a lower prevalence of anemia than non-smokers, although the difference was statistically insignificant.

About $30 \%$ of elderly were not wearing their footwear during outdoor activities, and this behaviour was associated with significantly higher prevalence of anemia $(p<0.05)$. Similarly, elderly who were drinking alcohol higher than safe limits (for survey identified as $>360 \mathrm{ml}$ i.e. 
Half a bottle/week) during last one month had a significantly higher prevalence of anemia as compared to those who were either non-drinkers or drinking within safe limits.
The study also revealed that elderly with history of chronic blood loss had a significantly higher prevalence of anemia.

Table 2: Distribution of Anemia based on Behavioural and Life Style-related Factor

\begin{tabular}{|c|c|c|c|c|c|}
\hline Characteristics/Factor & Variable & $\begin{array}{c}\text { Number Anemic } \\
n=92(\%)\end{array}$ & $\begin{array}{c}\text { Number Non-anemic } \\
n=239(\%)\end{array}$ & Total & $\begin{array}{l}\text { P value (Chi } \\
\text { square test) }\end{array}$ \\
\hline \multirow[t]{2}{*}{ Type of Diet } & Vegetarian & $24(29.3)$ & $58(70.7)$ & 82 & \multirow[t]{2}{*}{0.73} \\
\hline & Non-vegetarian & $68(27.3)$ & $181(72.7)$ & 249 & \\
\hline \multirow[t]{2}{*}{ Current Smokers } & Yes & $12(23.5)$ & $39(76.5)$ & 51 & \multirow[t]{2}{*}{0.54} \\
\hline & No & $80(28.6)$ & $200(71.4)$ & 280 & \\
\hline \multirow[t]{2}{*}{ Use of footwear outdoors } & Regular & $57(24.5)$ & $176(75.5)$ & 233 & \multirow[t]{2}{*}{$0.04 \#$} \\
\hline & Irregular & 35 (35.7) & $63(64.3)$ & 98 & \\
\hline \multirow[t]{3}{*}{ Alcohol } & Nil* & $35(24.3)$ & $109(75.7)$ & 144 & \multirow{3}{*}{$0.003 \#$} \\
\hline & $\begin{array}{l}\leq \text { Average of } 2 \text { units/day } \\
\text { during last } 1 \text { month* }\end{array}$ & $32(24.6)$ & $98(75.4)$ & 130 & \\
\hline & $\begin{array}{l}\geq \text { Average of } 2 \text { units/day } \\
\text { during last } 1 \text { month }\end{array}$ & $25(43.9)$ & $32(56.1)$ & 57 & \\
\hline \multirow{2}{*}{$\begin{array}{l}\text { History suggestive of Chronic blood loss } \\
\text { (bleeding PV or PR, malena }\end{array}$} & Present & $27(60.0)$ & $18(40.0)$ & 45 & \multirow[t]{2}{*}{$<0.001 \#$} \\
\hline & Absent & $65(22.7)$ & $221(77.3)$ & 286 & \\
\hline
\end{tabular}

* Rows combined for Chi-square test, \# statistically significant

One of the objectives of the study was to study the hypothesis that presence of social security in old age is associated with positive health. To study the concept of social security two variables were included (i) economic security defined as a reasonable income (arbitrary taken as Rs 500/- or more pm) directly available to the individual or his/her spouse (for e.g. from pension, old age pension, still earning, or money received by the elderly from his/her children) (b) psychological security defined as an individual living with his/her spouse. The results are shown in Figure 2.

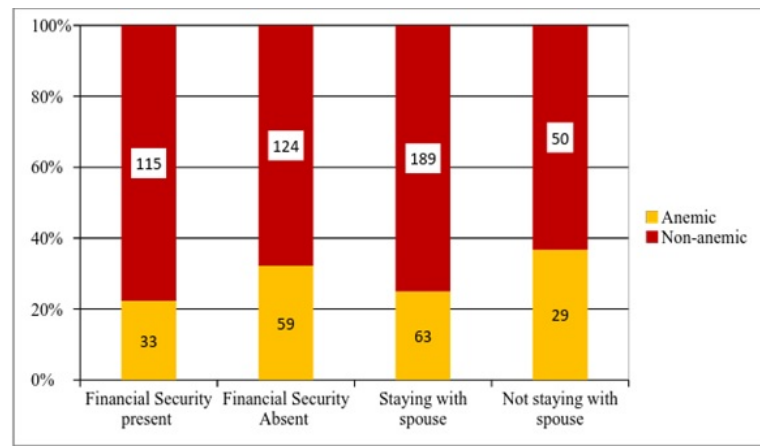

Fig-2: Association of Anemia with Economic and Psychological Security ( $p<0.05$ for both variables)
The analysis of the data revealed that presence of economic and psychological securities were independently associated with absence of anemia $(p<0.05)$.

\section{Discussion}

The study revealed that anemia is a significant public health challenge among elderly with prevalence rate of $27.79 \%$ (95\% CI $23.17-32.81 \%$ ). The prevalence rates among females were $33.3 \%$, while males had a prevalence rate of $21.9 \%$. WHO estimates that $23.9 \%$ (95\% CI $22.9-26.7 \%$ ) of elderly are anemic globally [3]. The prevalence rates estimated by this study are higher than the prevalence rates of $24.86 \%$ and $14.29 \%$ among females and males, respectively reported by Longitudinal Aging Study in India [10].

The present study revealed that the prevalence of anemia increased with the advancing years (Fig 1). This finding is consistent with a study conducted in US that also reported that prevalence of anemia increased as a function of age after 5th decade of life in both men and women [11]. The finding of this study that the prevalence of anemia was lower among smokers than non-smokers is consistent with results of a study by Nordenberg et al [12].

This paradoxical phenomenon is probably because the red blood cell production gets stimulated by 
Chronic exposure to carbon monoxide from cigarette smoke [13]. However, in this study confounding (as almost all smokers were males who have a significantly lower prevalence of anemia) may have also played a part. Significantly higher prevalence rates among those not using footwear is likely to be due to hookworm infestations.

Chronic loss of blood (bleeding per rectum or per vaginum) is an important cause of anemia in all age groups. In elderly this symptom deserves detail investigations to rule out neoplastic conditions. Fig 3 projects that that social security (both financial and psychological) as an associate of anemia. This aspect has not been studied earlier, and deserves validation from future studies before it can be labeled as 'causal'. Anemia among elderly is not only a game of numbers.

Studies in India and abroad have highlighted that anemia among elderly is caused by multiple causative factors $[14,15]$. A hospital based study [16] on anemia in India has identified nutritional deficiency $(30 \%)$, renal failure $(22 \%)$, chronic blood loss (31\%) and underlying malignancies (14\%) as important causes of anemia in elderly. Due to resource constraints this study was not planned for identification of type and causation of anemia.

\section{Conclusion}

As highlighted earlier, there is a lack of community based studies on prevalence of anemia among elderly in India. The study reveals that anemia among elderly is an important public health problem in India.

This challenge will obviously gain more significance in coming decades because demographic transition will increase absolute numbers and relative proportion of elderly. The authors recommend that anemia among elderly should be studied through larger studies including NFHS, so that the public health importance of the disease can be quantified in this demographic group at regional and national levels.

This will provide baseline data for planning intervention strategies to improve quality of life of our senior citizens. The Nation must ensure that its citizens, not only live longer, but enjoy a quality of life that they deserve. We feel that adding life to years is even more important than adding years to life.

\section{Reference}

01. WHO. Haemoglobin concentrations for the diagnosis of anaemia and assessment of severity. Vitamin and Mineral Nutrition Information System.

Accessed at: [Article] [Crossref]

02. de Benoist B, Mclean Erin, Egli I Cogswell. Worldwide prevalence of anaemia 1993-2005. WHO Global Database on Anemia.

Accessed at: [Article] [Crossref]

03. WHO. Global anaemia prevalence and number of individuals affected.

Accessed at: [Article] [Crossref]

04. Telangana State Fact Sheet. National Family Health Survey-4 (2015-16). International Institute for Population Sciences, Mumbai. 2016. Accessed at: [Article] [Crossref]

05. Strategy handbook. Rashtriya Kishor Swasthya Karyakaram. Government of India, Ministry of Health And Family Welfare, New Delhi. 2014.

Accessed at: [Article] [Crossref]

06. A Strategic Approach to Reproductive, Maternal, Newborn, Child and Adolescent Health $(\mathrm{RMNCH}+\mathrm{A})$ in India. Government of India, Ministry of Health and Family Welfare, New Delhi. 2013. Accessed at:

[Article] [Crossref]

07. Deb S. Implementation of National Iron Plus Initiative for Child Health- Challenges ahead. Indian J of Public Health. 2015;59(1)1-2.

Accessed at: [Article] [Crossref]

08. Eisenstaedt R, Penninx BW, Woodman RC. Anemia in the elderly- current understanding and emerging concepts. Blood Rev. 2006 Jul;20(4)213-26.

[Crossref]

09. WHO. Global Database on Anaemia. [Article] [Crossref]

10. Bloom D, Hu P, Arokiasamy P, Risbud A, Sekher TV, Mohanty SK, et al. Longitudinal Aging Study in India. RAND labor and Population. May 2014. Accessed at: [Article] [Crossref] 
11. Salive ME, Cornoni-Huntley J, Guralnik JM, Phillips CL, Wallace RB, Ostfeld AM, Cohen $\mathrm{HJ}$. Anemia and hemoglobin levels in older personsrelationship with age, gender, and health status. J Am Geriatr Soc. 1992;40(5)489-96.

Accessed at: [Article] [Crossref]

12. Nordenberg D, Yip R, Binkin NJ. The effect of cigarette smoking on hemoglobin levels and anemia screening. JAMA. 1990; Sep $26 ; 264(12) 1556-9$.

[Crossref]

13. Leifert JA. Anaemia and cigarette smoking. Int J Lab Hematol. 2008 Jun;30(3)177-84.

doi: $10.1111 /$ j.1751-553X.2008.01067.x [Crossref]
14. Patel KV. Epidemiology of anemia in older adults. Semin Hematol. 2008 Oct;45(4)210-7.

doi: 10.1053/j.seminhematol.2008.06.006 [Crossref]

15. Alwar V, Reethi K, Rameshkumar K. Geriatric anemia- an Indian perspective. Indian J Hematol Blood Transfus. 2013; Jun;29(2)126-7. doi: $\quad 10.1007 / \mathrm{s} 12288-012-0146-y \quad$ [Crossref]

16. Bhasin A, Rao MY. Characteristics of anemia in elderly- a hospital based study in South India. Indian J Hematol Blood Transfus. 2011 Mar;27(1)26-32.

doi: $\quad 10.1007 / \mathrm{s} 12288-011-0056-4 \quad$ [Crossref] 